\title{
Corneal graft rejection: a new rabbit model and cyclosporin-A
}

\author{
P. A. hunter, A. Garner. K. R. Wilhelmus, N. S. C. Rice. \\ AND B. R. JONES
}

From the Department of Clinical Ophthalmologv, the Institute of Ophthalmologv, and Moorfields Eve Hospital, London

SUMMARY In order to test the efficacy of topically applied cyclosporin-A in preventing corneal allograft rejection, existing rabbit models were modified to produce a new model in which the allograft reaction could be consistently initiated solely as a result of corneal transfer without any additional means of sensitisation. With this model, which reflects clinical corneal grafting more closely than many previous models, cyclosporin-A $1 \%$ drops applied to the recipient eye 5 times daily for 4 weeks inhibited corneal graft rejection. When cyclosporin-A $1 \%$ drops were applied to corneal allografts for 13 weeks, $44 \%$ of grafts remained clear 180 days after transplantation. No side effects were observed that could be attributed to topically applied cyclosporin-A.

Corneal grafts have been performed in animals ever since such surgery was first suggested in man. ' Early attempts in animals to explore the feasibility of such operations produced a variety of results, ${ }^{2-4}$ and much of the subsequent animal work was directed towards obtaining consistently clear grafts. ${ }^{5-8}$ As materials and techniques improved, many workers achieved success rates of $75-100 \%$ in animal models. ${ }^{9-13}$ and such work has laid the foundation for modern corneal graft surgery.

The recognition of the antigenicity of corneal tissue $^{14}$ and graft rejection in man ${ }^{15}$ has led to the development of new animal models in order to further understanding of the allograft reaction in man. Because of the difficulty in reproducing corneal graft rejection in animals by normal methods many of these experiments relied on additional means of sensitisation of the allograft, such as delayed skin transfer ${ }^{916}$ or transfer of previously sensitised lymphocytes, ${ }^{17}$ in order to produce a consistently high rejection rate. Another method used to encourage allograft rejection has been to promote vascularisation by the use of eccentrically placed lamellar grafts or delaying suture removal in centrally placed

Correspondence to Mr P. A. Hunter. FRCS. Department of Clinical Ophthalmology. Moorfields Fye Hospital. City Road. London FCIV 2PD. penetrating grafts, but many such grafts fail to undergo rejection. ${ }^{18}$ Xenografts have been found to have a consistently high rejection rate in animals. ${ }^{19} 20$ and both allograft and xenograft models have been used to investigate methods of suppressing the immune response by means of drug therapy. ${ }^{1921-23}$

Cyclosporin-A (CyA) administered by intramuscular injection has been reported to suppress the allograft reaction in a rabbit model which relied on additional skin transfer in order to sensitise the animal, ${ }^{24}$ though when applied topically to the recipient eve in the same model it had no effect. ${ }^{25}$ CyA, however, may have potentially serious side effects when administered systemically in man. ${ }^{26}$ and these would limit its use in clinical corneal grafting. It also appears that CyA acts early in the immune response and to be effective should be given at the time and place of sensitisation, ${ }^{26} 27$ which is not possible by topical application in existing models of the corneal allograft reaction.

We therefore set out to develop a new model of corneal graft rejection in which the allograft reaction is initiated solely as a result of the transplanted corneal tissue without any additional means of sensitisation. This would enable CyA to be delivered as a topical agent to a site where it may be effective. A new model is described together with the results of its use with various schedules of $\mathrm{CyA}$ treatment. 


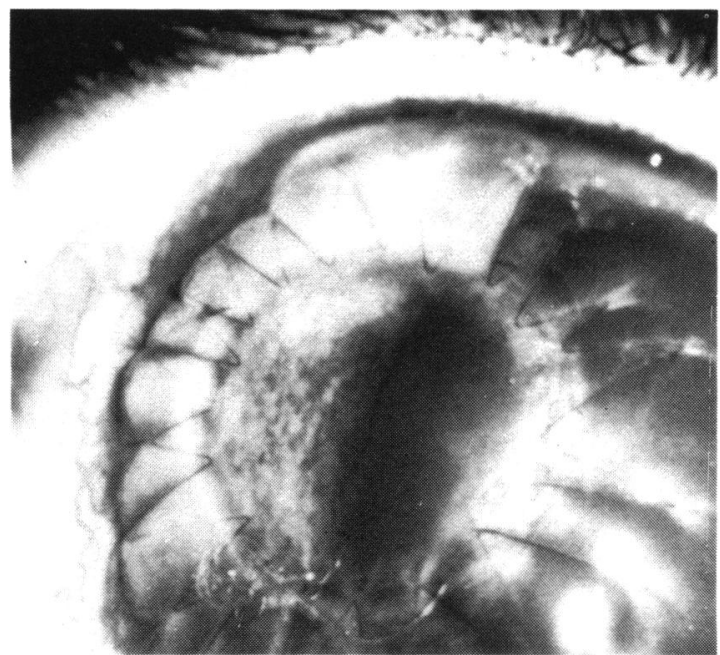

Fig. 1 Rabbit autograft (dav 4) sutured with contimuous $10 / 0$ monofilament nylon showing iris detail and dilated pupil edge through the clear graft.

\section{Materials and methods}

Outbred strains of Dutch and New Zealand white rabbits weighing between $(0.7$ and $3.8 \mathrm{~kg}$ underwent partial penetrating corneal grafts either as pairs for allografts (one of each type of rabbit) or singly for autografts. Preoperatively, the animals were given intravenous pentobarbitone sodium $(60 \mathrm{mg} / \mathrm{ml})$ in doses varying between 0.8 and $2.5 \mathrm{ml}$ according to their weight and response to the anaesthetic. Topical anaesthetic drops (proparacaine $\mathrm{HCl} 0.5 \%$ ) were instilled into their right eves together with drops of cyclopentolate $1 \%$ and phenylephrine $10 \%$ to achieve maximal dilatation of the pupil. $1 \mathrm{ml}$ of heparin $(5000$ units $/ \mathrm{ml})$ was given intravenously to each animal in order to prevent clotting of the secondary aqueous. All operations were performed under an operating microscope.

OPERATIVE TECHNIQUE

After fixation of the eve by means of $4 / 0$ silk sutures to 2 recti muscles a $6 \mathrm{~mm}$ trephine was used to perform a partial penetrating keratoplasty placed eccentrically in the upper temporal quadrant of the right cornea of each animal. The graft was positioned in such a way that a $1-2 \mathrm{~mm}$ margin of host cornea was visible at the point where the graft came nearest to the limbus. After the anterior chamber was entered with the trephine, the incision was completed with corneal scissors. The corneal discs were then interchanged and held in place initially with 4 interrupted 10/0 monofilament nylon sutures which were removed at the end of the operation. A continuous $10 / 0$ monofilament nylon suture was then used to secure the graft with the knot placed on the side of the graft nearest the limbus in order to encourage vascularisation. with no attempt being made to bury the knot (Fig. 1). The anterior chamber was not artificially reformed; thus the iris was left in contact with part of the corneal wound to promote the formation of synechiae and subsequent deep corneal vascularisation. At the end of the procedure chloramphenicol ointment was placed on the operated eve at the same time as some animals received their first dose of $\mathrm{CyA}$. Autografts were performed in an identical manner except that the discs were sutured back into the same animal.

POSTOPERATIVE MANAGEMENT

All animals received atropine $1 \% / r$ drops and chloramphenicol ointment daily until the removal of the corneal suture on the 14th day. On the first postoperative dav slit-lamp examination was carried out and the following points were noted: the clarity of the graft and host cornea. anterior chamber depth and reaction. extent of corneal/iris adhesions, and any evidence of lens damage. Subsequent dailv slit-lamp examinations were performed to assess the rate of the clearing of the graft. the progression of vascularisation. and any evidence of uveitis or allograft reaction.

CORNEAI. REVASCUIARISATION

In order to investigate the mechanism of graft tolerance in 6 animals whose corneal grafts had remained clear for longer than 6 months silver nitrate was applied to the corneal surface at the graft-host interface. A series of small burns were produced with a crystal of silver nitrate leaving the central graft area unaffected. The procedure was repeated after an interval of 2 davs, and the animals were ohserved for signs of vessel reactivation and evidence of allograft rejection in the central graft area.

DIAGNOSIS OF THE AIIIOGRAFT REACTION

The appearance of one or more of the following clinical signs was taken to indicate the onset of the allograft reaction ${ }^{28}$ : (1) the clouding of a part or all of the corneal stroma in a graft which had previously been clear; (2) epithelial rejection line: (3) endothelial rejection line.

Graft survival was then recorded in davs from the date of surgery until the first day on which any of these signs appeared. Usually the progression of the allograft reaction was observed for a few davs in order to confirm the diagnosis before the animal was killed. The whole eye was then removed and placed in $10 \%$ formal saline. 
HISTOI.OGICAL. METHODS

After fixation the globes were opened either parallel to the antero-posterior axis to provide sections of the whole eye, or, more usually, the anterior segment alone was processed. Sections of paraffin-embedded material cut so as to include the limbal and central margins of the eccentrically located graft were stained with haematoxylin and eosin and by the periodic acidSchiff sequence. In 2 instances in which punctate opacities were observed in the donor cornea frozen sections were prepared for the demonstration of lipid by means of oil red 0 and Sudan black stains.

CYCLOSPORIN-A

A number of rabbits in the study were treated on a coded basis with either intramuscular CyA for 2 weeks (18 rabbits) or CyA $1 \%$ in arachis oil applied topically to the recipient eye 5 times daily for an initial period of 4 weeks ( 30 rabbits). In the intramuscularly treated group 8 rabbits received a dosage of $25 \mathrm{mg} / \mathrm{kg}$ for 2 weeks, as this dose had been used in previous studies. ${ }^{223}$ This was later reduced to $15 \mathrm{mg} / \mathrm{kg}$ in the remainder of the group in an attempt to minimise side effects. In the topically treated group 9 rabbits continued treatment for a total of 13 weeks, but on a reducing dosage (twice daily for 5 weeks then once daily for 4 weeks). Out of the control group (33 rabbits) 14 rabbits received topical arachis oil drops 5 times daily, thus acting as a simultaneous control group for those animals receiving topical CyA in a fully coded trial.

EXCI.USION FROM RESULTS

Nineteen out of 88 rabbits were excluded from the

Table 1 Surgical factors leading to exclusion from results in 19 out of 88 rabbits undergoing penetrating keratoplasty

\begin{tabular}{ll}
\hline & No. of rabhits \\
\hline Flat anterior chamber & 7 \\
Endothelial damage & 3 \\
Lens damage & 3 \\
Postoperative hyphaema & 2 \\
Anaesthetic deaths & 2 \\
Infected graft & 1 \\
No iris adhesions & 1 \\
\hline
\end{tabular}

Table 2 Late deaths occurring in 9 out of 69 rabbits undergoing penetrating keratoplasty according to type of graft and treatment

\begin{tabular}{lll}
\hline Group (total rabbits in group) & No. of deaths & 7\% Deaths/group \\
\hline Autografts (7) & - & 0 \\
Allografts-controls (25) & 1 & $4 \%$ \\
Allografts-topical CyA (24) & 2 & $8 \cdot 4 \%$ \\
Allografts-systemic CyA (1.3) & 6 & $46.2 \%$ \\
\hline
\end{tabular}

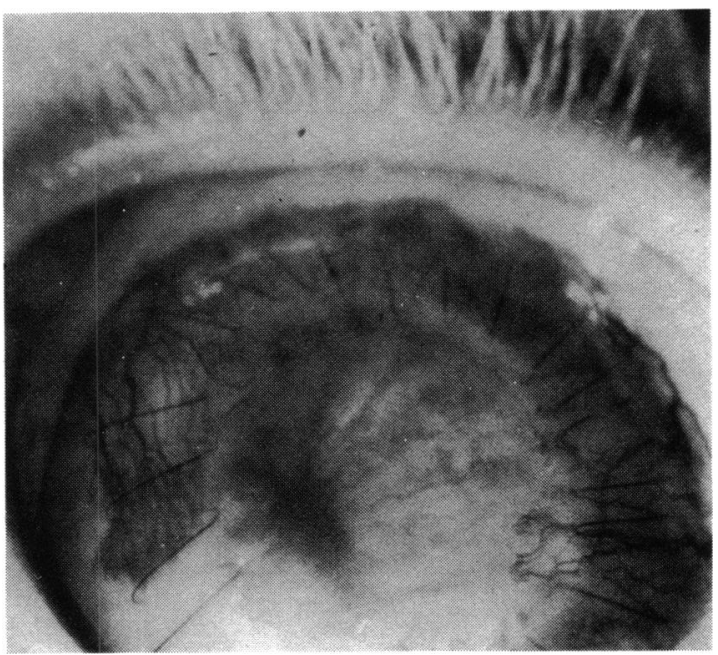

Fig. 2 Rabbit allograft (dav 14) showing a clear graft with ingrowing vessels around suture line.

analysis of results because of complications in the immediate postoperative period (Table 1) and 9 rabbits because they failed to survive to a point where their grafts underwent rejection (Table 2).

\section{Results}

All allografts in the control groups (including those that had received topical arachis oil to the recipient eve) underwent rejection. In the groups treated with CyA the onset of rejection was delayed in 24 animals and failed to occur in the remaining 5 after 180 davs. The autografted group retained clear grafts for periods longer than 6 months. These results are described below.

\section{CLINICAI. COURSE}

After transplantation all grafts cleared between the first and seventh day except in the part which was adjacent to the site of iris/graft adhesions. These involved between $90^{\circ}$ and $180^{\circ}$ of the circumference of the graft lying closest to the limbus. In addition a rim of oedema persisted along the suture line in the donor and host cornea. This oedema was thought to be related to retraction of Descemet's membrane or to endothelial trauma at the time of surgery. Superficial vessels started to grow from the limbus and reached the graft/host interface by the end of the first week, after which they progressed around and into the graft. By the time of the removal of the suture on the 14th postoperative day they usually involved three-quarters of the graft's circumference (Fig. 2). Deeper vessels arising from the iris also invaded the graft to a lesser degree. 


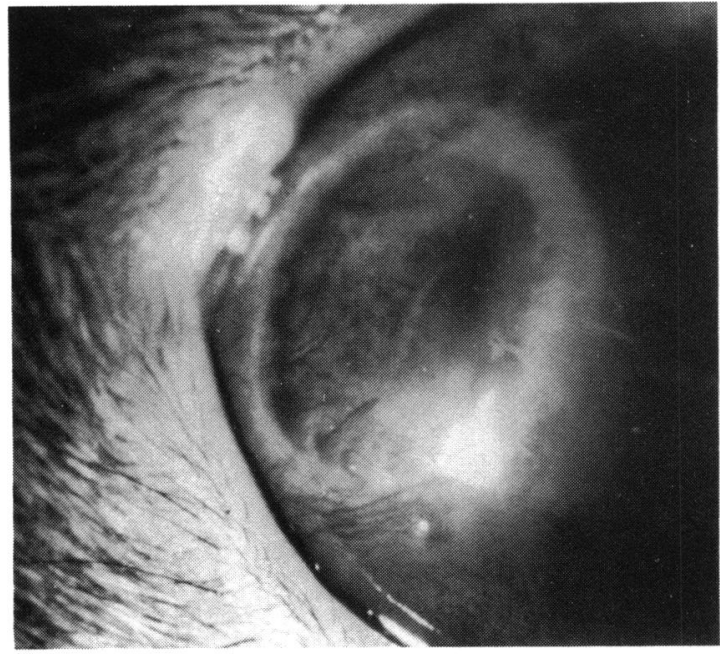

$3 \mathrm{a}$

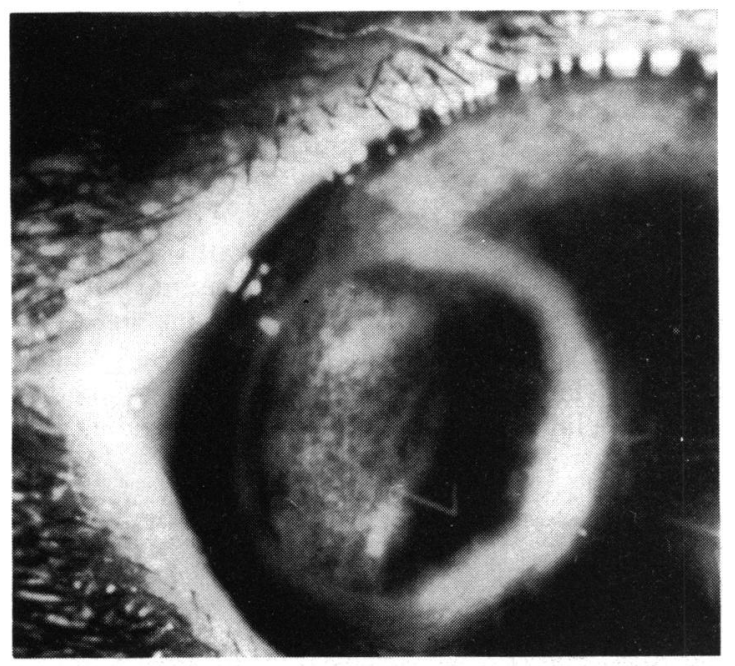

$3 b$

Fig. 3 Rabbit autograft (the same animal as Fig. I) showing (a) a clear graft with vascular ingrowth (day 18) and (b) a clear graft with scar tissue at the graft/host interface and complete regression of vessels (dav 46).

In those animals undergoing autografts or allografts treated with CyA, after the removal of the suture vessels continued to grow around the host/graft interface where some residual oedema persisted (Fig. 3a). Then during the third and fourth weeks the vessels gradually became less active and by the fifth or sixth week were visible only as 'ghost' vessels (Fig. 3b). This complete regression of vessels was not observed in the control groups, as the rejection process supervened during this period.

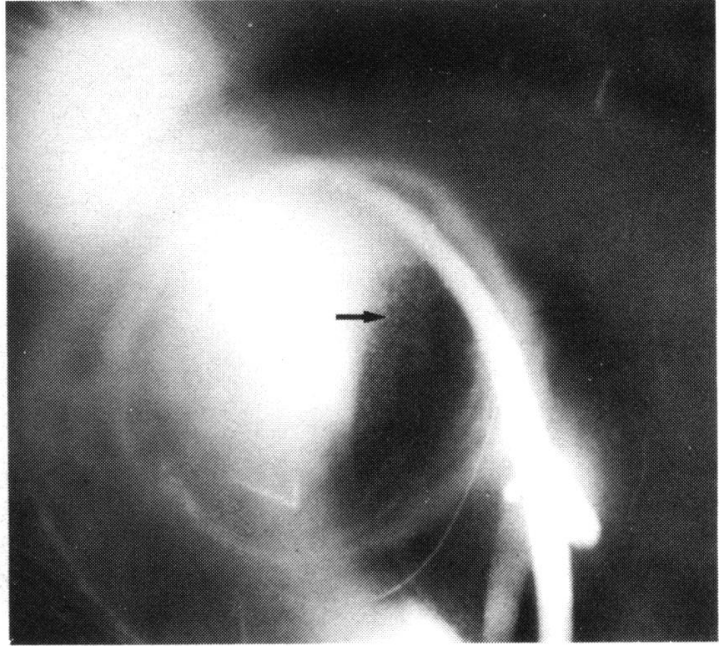

Fig. 4 Rabbit autograft (dav 44) viewed with slit illumination showing superficial stromal punctate opacities (arrowed) in an otherwise clear graft.

A small number of rabbits developed collections of punctate opacities close to ingrowing vessels in the superficial stroma of an otherwise clear cornea. These later tended to coalesce and assume a refractile appearance, suggesting the presence of lipid. They were not thought to represent any part of the immune reaction, because they occurred in both host and graft and, in 2 cases, in autografted rabbits (Fig. 4). Histologically several small extracellular deposits of lipid were demonstrable in appropriately processed sections of the donor cornea immediately beneath the epithelium (Fig. 5). There was no sign of leucocytic infiltration, and the lipid was presumed to have originated from the adjacent intracorneal blood vessels.

The histology of all the autografted corneas showed healing. with negligible scar tissue formation and no retrocorneal fibrosis. Corneo-irideal adhesions were apparent in 5 of the animals, with some residual vascularisation in one. but there was no leucocytic infiltration, and the donor epithelium. stroma, and endothelium appeared healthy in every instance. There was therefore no evidence of rejection in any of the autografted animals.

\section{AI.I.OGRAFT REACTION}

All 3 clinical features by which the allografts reaction may be recognised in corneal grafts ${ }^{2 x}$ were observed in each group of allografts (Table 3 ). The process of rejection seen in this series of allografts appeared to correspond almost exactly with previous descriptions of the allograft reaction in various corneal layers. ${ }^{28}$ 
Fig. 5 Rabbit autograft.

Immediately deep to the epithelium in the grafted cornea there are small extracellular deposits of lipid. (Frozen section: oil red 0 and haematoxylin, $\times 385)$.

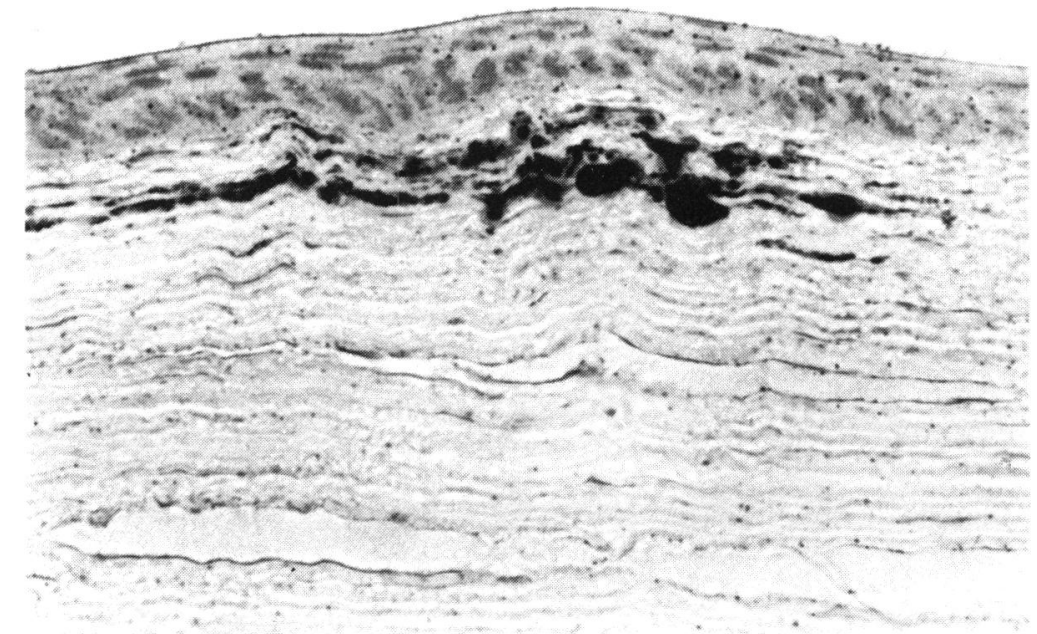

Table 3 Types of corneal graft rejection seen in 60 rabbits undergoing penetrating keratoplasty

\begin{tabular}{lllll}
\hline Group & \multicolumn{2}{l}{ Rejection } & & $\begin{array}{l}\text { No } \\
\text { rejection }\end{array}$ \\
\cline { 2 - 4 } & $\begin{array}{l}\text { Graft } \\
\text { oedema }\end{array}$ & $\begin{array}{l}\text { Endothelial } \\
\text { rejection }\end{array}$ & $\begin{array}{l}\text { Epithelial } \\
\text { rejection }\end{array}$ & \\
\hline $\begin{array}{c}\text { Autograft } \\
\text { Allograft } \\
\text { (Control) }\end{array}$ & - & - & - & 7 \\
$\begin{array}{c}\text { Allograft } \\
\text { (Top.CyA) }\end{array}$ & 4 & 2 & 9 & - \\
$\begin{array}{c}\text { Allograft } \\
\text { (Syst.CyA) }\end{array}$ & 1 & 6 & 7 & 5 \\
Total & 18 & 3 & 2 & 1 \\
\hline
\end{tabular}

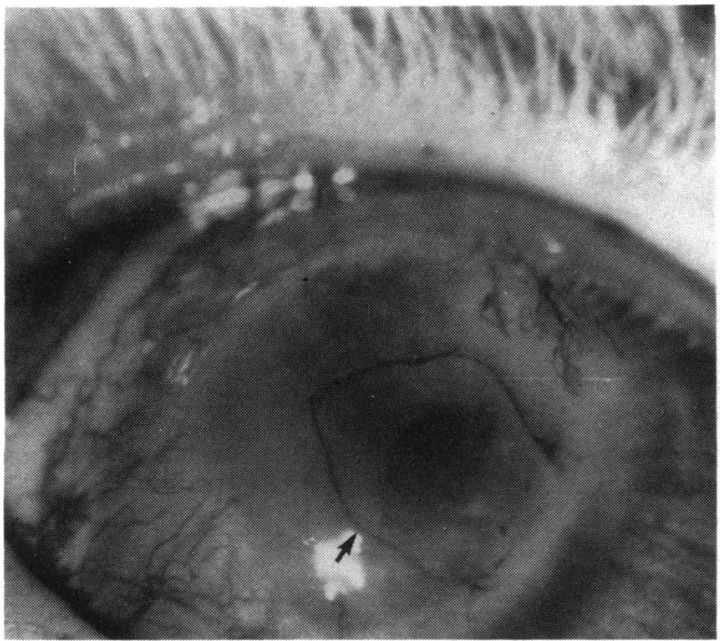

Fig. 6 Rabbit allograft (day 38) treated with topical CyA drops from day 0 to day 28 showing advancing epithelial rejection line stained with methylene blue (arrowed).
Graft rejection always started near invading blood vessels, usually at the site of maximal vascularisation, and progressed into previously clear cornea. In any one corneal layer the rejection process was usually established in the whole graft within 7 days of its onset, although in those animals treated with CyA the process took up to 14 days. Epithelial rejection lines could progress rapidly across the graft (Fig. 6) with only minimal disturbance in the anterior stromal layers, but this was then followed about one week later by the appearance of stromal or endothelial rejection (Fig. 7). Where the reaction was confined to the epithelium and anterior stroma, no evidence of

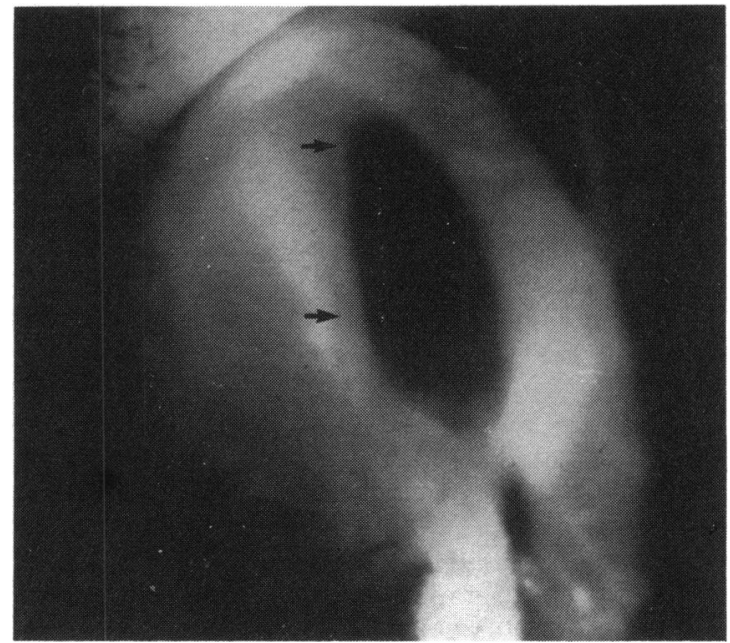

Fig. 7 Rabbit allograft (day 81) treated with topical $C y A$ drops from day 0 to day 91 showing endothelial rejection line (arrowed) viewed partly by retroillumination. 


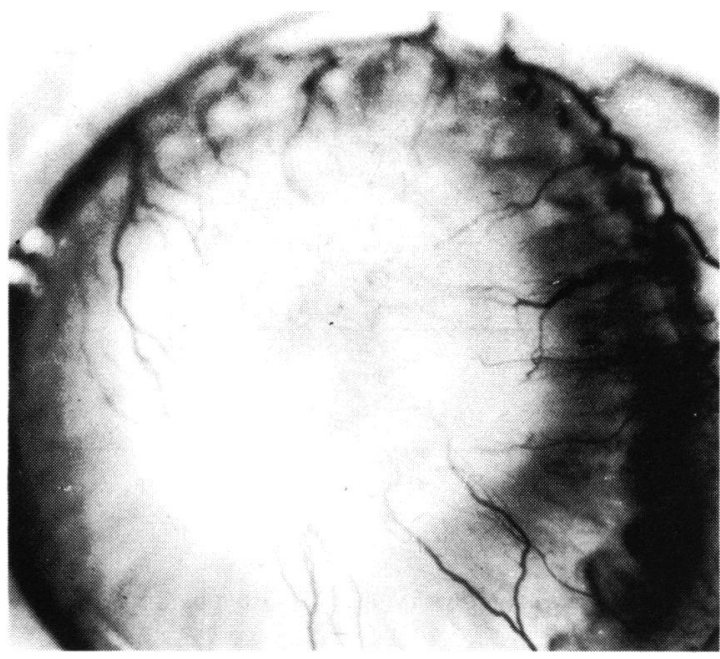

Fig. 8 Rabbit allograft (the same untreated control animal shown in Fig. 2) showing total rejection with opacification and complete vascularisation of the graft (dav 28).

uveitis was seen. Even in those cases that developed endothelial rejection lines only a few cells were seen in the anterior chamber. Eighteen out of 60 clear grafts developed diffuse graft oedema (Fig. 8) without endothelial or epithelial rejection lines, and this appearance was subsequently confirmed as being due to the allograft reaction on histopathological grounds.

On histological examination stromal vascularisation was observed in most control animals (21 of 24 eyes) and was best seen on the limbal side of the graft, where there was cornea-irideal adhesion. Inflammatory cell infiltration, mainly in the form of lymphocytes and plasma cells with a few neutrophil polymorphonuclear leucocytes, was associated with the vascular incursions and was a feature of all specimens. Scar tissue proliferation extending from the deep surface to create limited retrocorneal fibrosis at the graft margins was observed in half the specimens. Attenuation and loss of the endothelium of variable extent with attendant stromal swelling were present in slightly more than half the specimens (Fig. 9). Keratic precipates consisting of mononuclear cells were seen in most corneas showing endothelial damage. Epithelial atrophy was apparent in the grafted corneas of most animals. All grafts in the untreated control group showed signs of immunological rejection.

All grafts in the control group underwent rejection by the 34th day, with the first graft being rejected on the 8 th postoperative day (Figs. 10 and 11). The mean

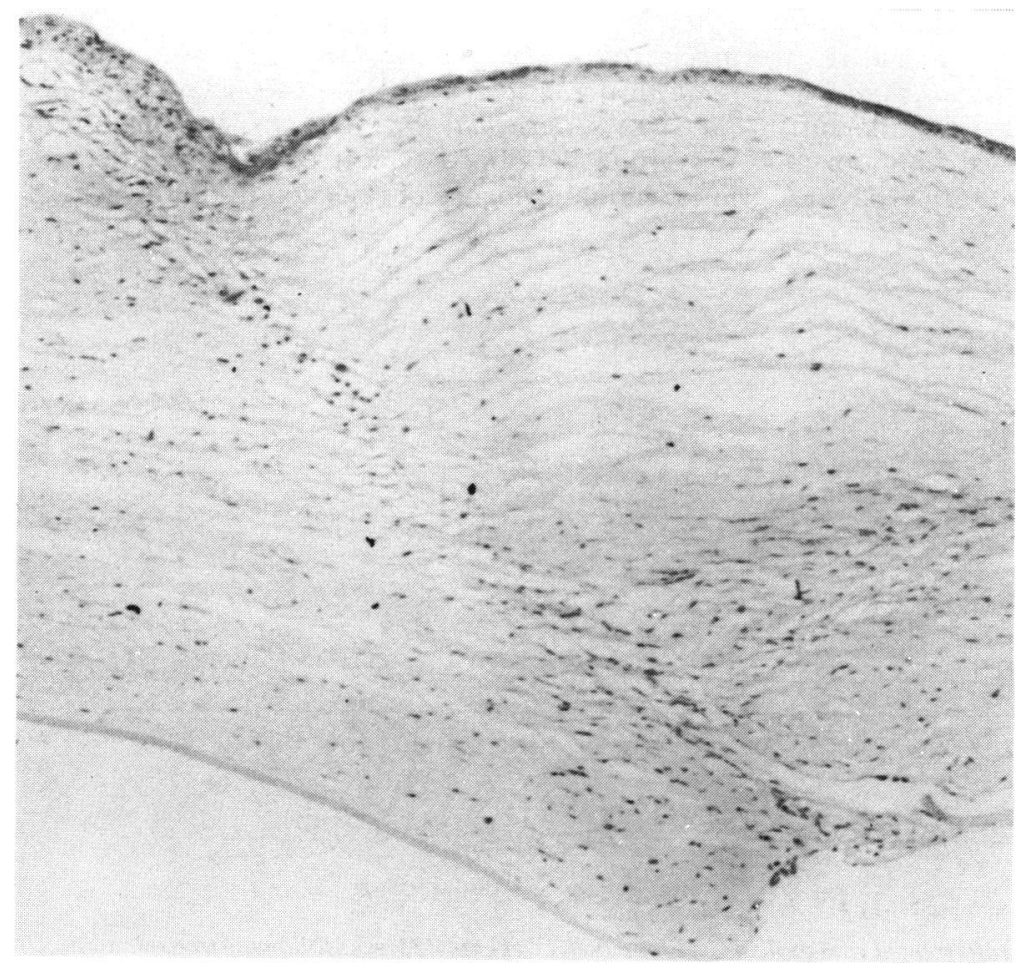

Fig. 9 Graft-host interface displaving absence of endothelium on Descemet's membrane of the donor tissue and a little leucocvtic infiltration of the graft margin. (Haematoxylin and eosin, $\times 107$ ). 


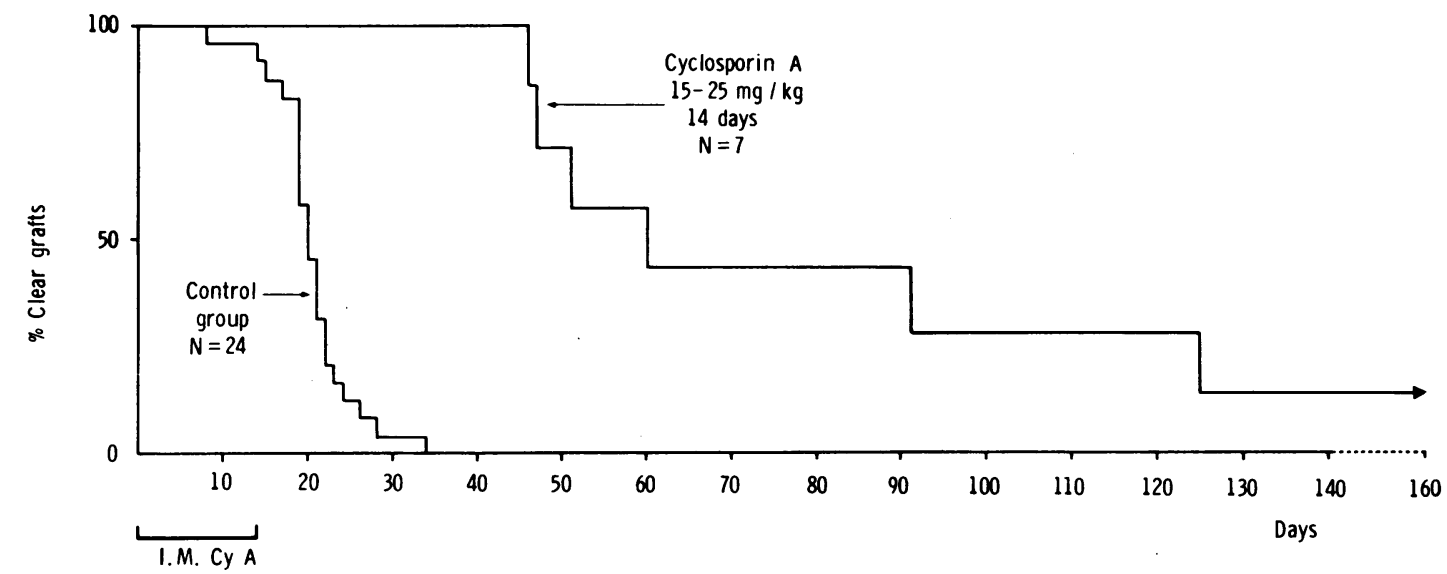

Fig. 10 Survival of rabbit corneal allografts treated with intramuscular $C y A$ for 14 days following transplantation.

survival time of grafts in this group was $20 \cdot 78 \pm \mathrm{SD}$ $4 \cdot 80$ days. The earliest rejection occurred in a New Zealand white rabbit, in which rapid vascularisation of the graft was quickly followed by the appearance of an epithelial rejection line on the eighth postoperative day. No difference was found between Dutch and New Zealand white rabbits concerning the time or rate of rejection.

CYCLOSPORIN-A

The survival rates of 3 groups of corneal allografts treated with CyA are shown in the Figs. 10 and 11.

(a) Seven rabbits treated with Intramuscular $C y A$ $(15-25 \mathrm{mg} / \mathrm{kg})$ for 2 weeks. Six of the 7 allografts showed a prolonged period of survival with a mean survival time of 98 days compared with $20 \cdot 78$ days for the control group. $(p<0 \cdot 001)$. One graft in this group remained clear at 180 days (Fig. 10).

(b) Thirteen treated with topical $\mathrm{Cy} A 1 \%$ in arachis oil to the recipient eye 5 times daily for 4 weeks. The first allograft in this group was rejected on day 31,3 days after stopping treatment (Fig. 6), and the remainder had all been rejected by day 77 , with a mean survival time of $47 \cdot 31 \pm 12 \cdot 56$ days. Compared with the control group this gave a $p$ value of $<0.001$ (Fig. 11).

(c) Nine rabbits treated with topical CyA $1 \%$ in arachis oil to the recipient eye for 13 weeks with a reducing dosage (5 times daily for 4 weeks, twice daily for 5 weeks, once daily for 4 weeks). Two allografts in this group developed typical endothelial rejection lines without evidence of rejection in the superficial

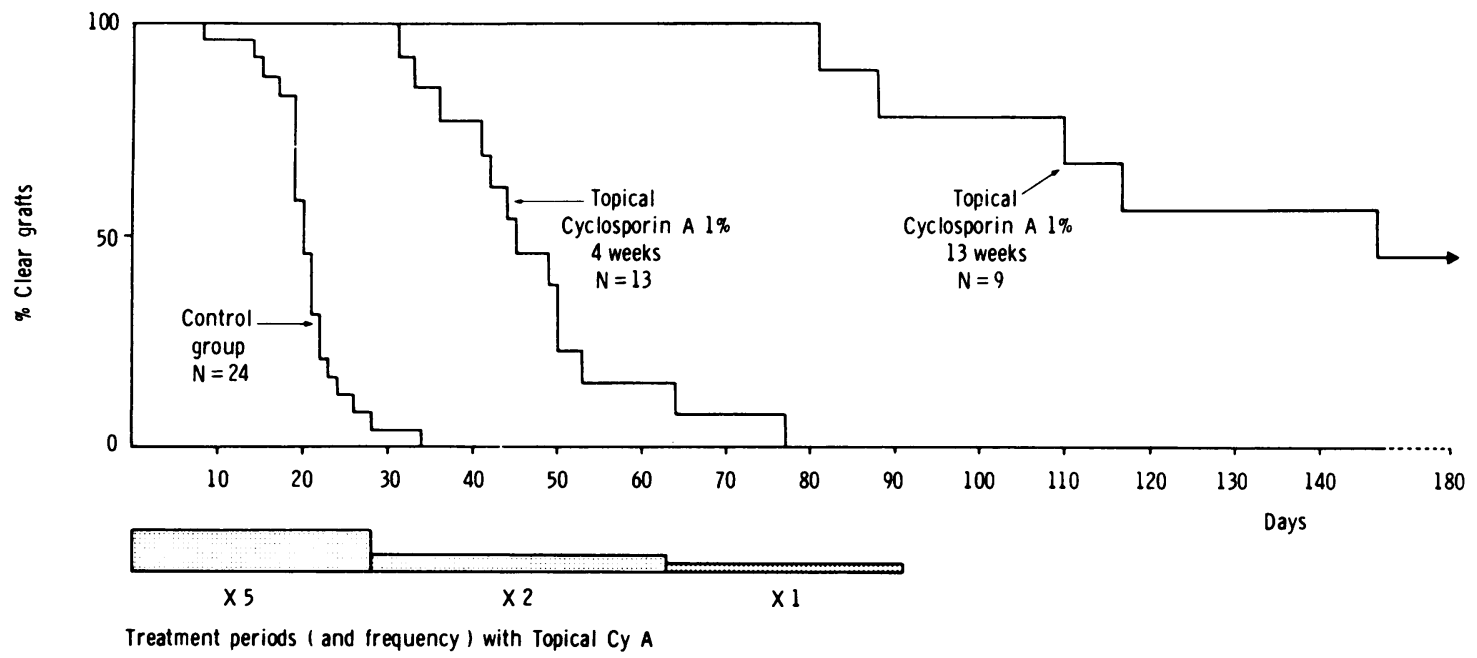

Fig. 11 Survival of rabbit corneal allografts treated with topical CyA for either 4 weeks or 13 weeks following transplantation. 
stroma or epithelium before treatment was stopped (Fig. 7). These developed on days 81 and 88 respectively, more than 2 weeks after the treatment had been reduced from twice to once daily. Of the remaining 7 rabbits 3 rejected the grafts (days 110 , 117 , and 147), while the others remained clear for more than 180 days (Figs. 11 and 12 ).

On histological examination all animals killed after treatment with CyA for the prescribed period showed signs of rejection manifested by endothelial cell loss, stromal swelling, and reduced thickness of the epithelium. Leucocytes were conspicuous at the graft margins in virtually every case, and in most instances inflammatory cells with newly formed blood vessels had spread into the donor tissues (Fig. 13). There was no evidence of surgical failure, the graft margins being fully healed in all specimens.

\section{EFFECT OF CORNEAL REVASCULARISATION ON GRAFT SURVIVA L}

Six animals which had maintained clear corneal grafts for longer than 6 months had their corneas revascularised by means of silver nitrate. The group consisted of 1 autograft, 1 allograft treated with intramuscular CyA $15 \mathrm{mg} / \mathrm{kg}$, and 4 allografts which had been treated with topical CyA for 13 weeks. All corneas initially developed mild central graft oedema which cleared within a few days, associated with marked vessel reactivation in the host and graft stroma.

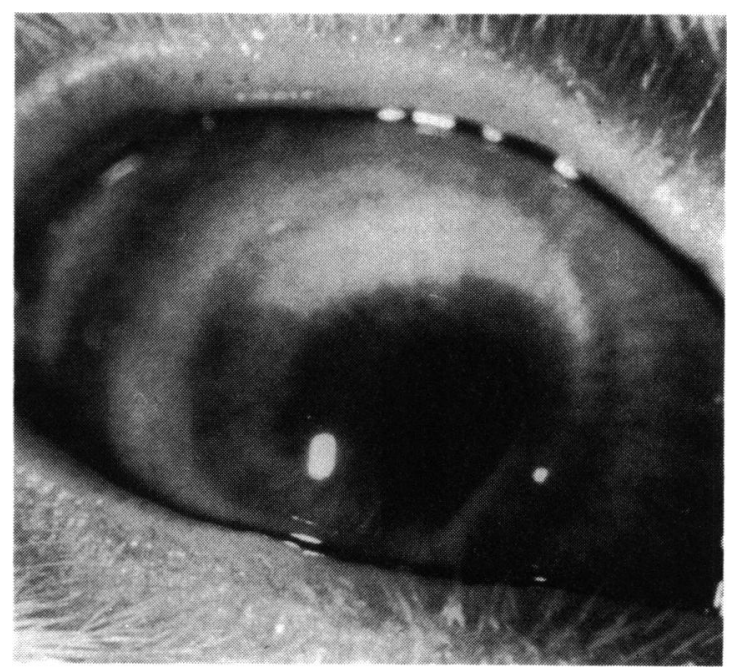

Fig. 12 Rabbit allograft (day 150) showing a clear graft following treatment with topical CyA from day 0 to day 91 .

The autograft remained clear. The allograft which had been treated with systemic CyA developed a typical allograft reaction on the 12th day. Three out of the 4 allografts treated with CyA developed allograft reactions on the 14th, 24th, and 30th days, while the fourth developed a sustained inflammatory response lasting 5 weeks, though it later settled leaving a clear graft.

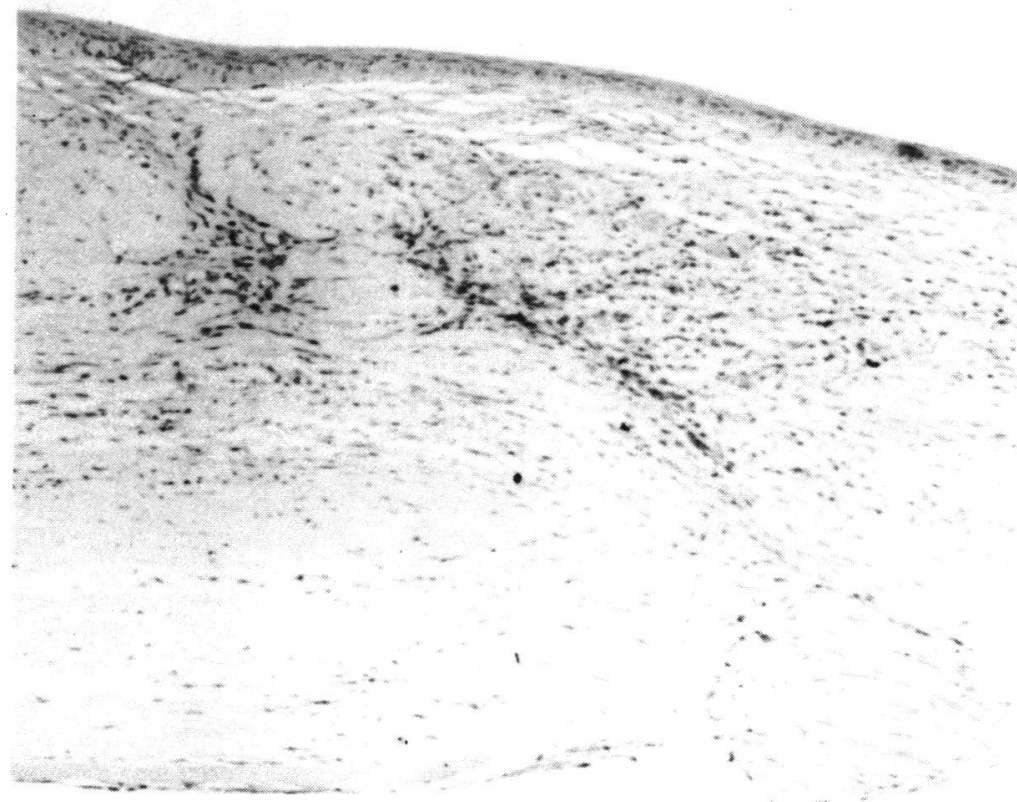

Fig. 13 Graft-host interface showing vascularisation and leucocytic infiltration of the stroma associated with graft rejection. The donor stroma (on the left) is swollen and the donor endothelium is atrophic. (Haematoxvlin and eosin. $\times 107)$ 
SIDE EFFECTS OF CYCLOSPORIN A

(a) Intramuscular CyA $15-25 \mathrm{mg} / \mathrm{kg}$. Nine out of 11 rabbits surviving for longer than 2 weeks lost weight. and the mean weight loss for the whole group during the first 2 weeks was $0 \cdot 19 \mathrm{~kg}$. All other groups of animals over the same period had mean weight gains which were as follows: autografts $+0.175 \mathrm{~kg}$, allografts (controls) $+0 \cdot 22 \mathrm{~kg}$, allografts (treated with topical CyA) $+0 \cdot 07 \mathrm{~kg}$. Although this weight loss was not statistically significant, it was a notable clinical feature of the animals treated systemically during the first 2-3 weeks. After stopping CyA treatment the rabbits later regained their initial weight by about the 5 th week.

In the group overall, 6 out of 13 died before their grafts were rejected (Table 2), though one was killed for reasons that could not be related to the drug. The 5 deaths $(42 \cdot 6 \%)$ occurred on days $14,15,27,35$, and 83 among animals receiving both high ( 2 rabbits) and low (3 rabbits) dosages. The greater death rate in this group compared with controls and topically treated groups was significant $(0 \cdot 05>\mathrm{p}>0 \cdot 01, t$ test $)$.

(b) Topical $C y A 1 \%$. Two out of $24(8 \cdot 3 \%)$ rabbits died before their grafts underwent rejection, which when compared with 1 death in the control group $(4 \%)$ was not significant (Table 2 ). One death in the topically CyA-treated group was associated with a 2-day episode of diarrhoea occurring 10 days after treatment was stopped (day 38), and the other death occurred on day 25.

All rabbits in the groups treated with either topical CyA in arachis oil or arachis oil alone lost varying amounts of fur round the treated eye (Fig. 14). This fur loss appeared after about one week and remained while treatment was continued. However, within 4-5 days of stopping treatment the fur started to regrow in all cases. Conjunctival changes were confined to mild hyperaemia of the bulbar and palpebral conjunctiva in rabbits treated with both arachis oil alone and $\mathrm{CyA}$ $1 \%$ in arachis oil.

\section{Discussion}

Although many possible mechanisms for the development of the corneal allograft reaction in man have been proposed, ${ }^{29}$ the exact routes by which rejection may be brought about has not yet been established. Systemic mechanisms may be important in circumstances where the possibility of presensitisation by transplantation (HLA system) antigens exists, for example, from previous corneal grafts, pregnancy, or blood transfusions. ${ }^{3031}$ The role of the blood group antigens (ABO system), however, is less clear, and they would certainly not appear to represent a major factor in clinical corneal allograft rejection. ${ }^{32}{ }^{33}$ As a means of studying such 'second set' allograft

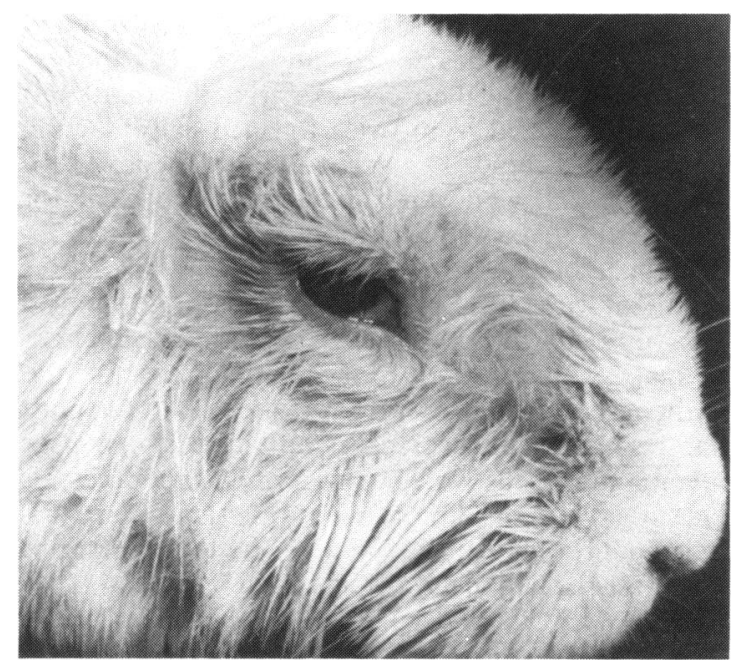

Fig. 14 Loss of fur around eve of New Zealand white rabbit treated for 4 weeks with arachis oil drops 5 times daily for 4 weeks (dav 28).

reactions animal model utilising additional methods of sensitisation have been widely practised, yielding much valuable information. ${ }^{161721-25}$

However, clinical corneal allograft reactions frequently occur where sensitisation would appear to have resulted only from the transfer of corneal tissue following a first graft, and to date no satisfactory 'single set' animal model has been reported. Animal models involving xenografts may induce morphological changes in lymph nodes throughout the body of a rabbit, whereas allografts in the same animal would appear to produce local lymphoid changes only. ${ }^{34}$ There may therefore be fundamental differences between rejection of a xenograft and allograft, which makes comparison of xenograft models with clinical allografting difficult. Corneal allograft rejection by a 'single set' mechanism has been demonstrated in rabbits by means of lamellar grafts, but it was found that only $48 \%$ of grafts underwent rejection over a period of 2-6 weeks. ${ }^{35}$ In another 'single set' model of allograft rejection involving penetrating grafts $72 \%$ of grafts took between 2 and 12 weeks to undergo rejection, leaving $28 \%$ unrejected at the end of this period.

The present model has several advantages over previous models. Firstly, $100 \%$ of untreated grafts were rejected over a period of 1-5 weeks, with a mean survival time of $20 \cdot 78 \pm \mathrm{SD} 4 \cdot 80$ days. As ingrowing vessels normally take 5-7 days to reach the graft, this may indicate that the model is a more severe immunological challenge than previous systems. Secondly, rejection appears to occur as a 
result of a 'single set' allograft reaction, making it a closer analogue of the majority of clinical corneal graft rejections. Thirdly, it has been suggested that local immune mechanisms may be responsible for all or a substantial part of corneal allograft reactions, ${ }^{29} 36$ and these might be altered by the local use of immunosuppressive agents. The effects of the topical use of such agents might not be observed where a model depended on additional distant sites of sensitisation. Thus, when CyA was administered topically in a 'second set' model in which it was known to be effective systemically, it failed to prevent graft rejection, ${ }^{25}$ yet when applied topically to the grafted eye in our 'single set' model it was able to inhibit rejection.

The ability of CyA to inhibit graft rejection when applied topically to the recipient eye for 4 weeks has already been reported, and these results have been discussed elsewhere. ${ }^{36}$ In the present experiments graft survival was further prolonged by continuing the drug for a period of 13 weeks, though the fact that 2 grafts underwent rejection while still on therapy may suggest that the treatment frequency was reduced prematurely. Even so, $44 \%$ of grafts remained clear for periods of over 3 months after treatment was stopped. It is possible that specific immunological tolerance may be induced by $\mathrm{CyA}$, as has been suggested by work in other organ transplantation models. ${ }^{37}$ However, in this model, when the experiment was carried out to produce reactivation of the corneal blood vessels, 4 out of 5 allografts rapidly developed typical corneal rejection in spite of previous treatment with $\mathrm{CyA}$. It would therefore appear that the most important factor in producing graft tolerance in this model was the regression of the corneal vessels while CyA treatment was maintained. during which time the relative immunological privilege of the cornea was restored.

No side effects that could be attributed to topical CyA were found. The previously reported ${ }^{2538}$ transient loss of fur that occurred round the eves of treated rabbits was found to be due to irritation by the arachis oil and subsequent scratching by the rabbit. By contrast with the rabbits treated with systemic CyA, which showed weight loss and a significantly increased death rate, the results to date indicate that topical CyA appears to be a safe drug. though this needs to be fully established by further detailed investigation.

It is hoped that the ability of topically applied CyA to inhibit corneal allograft rejection in a single-set rabbit model will enable clinical trials to begin shortly.

\section{References}

1 Darwin E. Zoonomia or the Laws of Organic Life. 1796: 2.

2 Reisinger F. Baiersche Annalen fuer Ahhandlungen.
Erfindwingen und Beobachtunger aus dem Gehiete der (hirurgie. Augenheilkunst und Gehurtshuelfe. Salzabech: 1824: 1: Ch. 15: $207-15$.

3 Bigger SL. An inquiry into the possibility of transplanting the cornea with the view of relieving blindness (hitherto deemed incurable) caused by several diseases of that structure. Dublin Journal of Medical Sciences 18.37; 11; 408-47.

4 Power H. On transplantation of the cornea. Proceedings of IVth International Ophthalmological Congress 1872. London: 1873: $172-6$.

5 Tudor-Thomas JW. Transplantation of the cornea: a preliminary report on a series of experiments on rabbits. together with a demonstration of four rabbits with clear corneal grafts. Trans Ophthalmol Soc UK 1930: 50: 127-41.

6 Castroviejo R. Keratoplastv-microscopic studv of corneal grafts. Trans Am Ophthalmol Soc 1937: 35: 355-85.

7 Stansbury F. Wadsworth JA. Corneal transplantation in rabhits. Am J Ophthalmol 1947: 30: 968-78.

8 Babel J, Bourquin JB. Experiment research with corneal heterografts. Br J Ophthalmol 1952: 36: 529-36.

9 Greaves DP. Experimental penetrating keratoplasty. Trans Ophthalmol Soc UK 1954; 74: 135-44.

10) Khoudadhoust AA. Penetrating keratoplasty in the rabbit. Am J Ophthalmol 1968; 66: 899-9(5)

11 Khoudadhoust AA. Lamellar corneal transplantation in the rabbit. Am J Ophthalmol 1968; 66: 1111-7.

12 McEntvres JM. Experiment penetrating keratoplasty in dogs. Arch Ophthalmol 1968: 80: 72-6.

13 Polak FM. Corneal Transplantation. New York: Grune and Stratton. 1977: Ch. 1: 3-11.

14 Billingham RE. Boswell T. Studies on the problem of corneal homografts. Proc $R$ Soc Lond (Biol) 1953: 41: 392-41k.

15 Paufique L. Sourdille GP. Offret G. Les Cireffes de la Cornée. Paris: Masson. 1948: 258-9

I6 Maumenee AF. The influence of donor-recipient sensitisation on corneal grafts. Am J Ophthalmol 1951: 34: 142-52

17 Khoudadhoust AA. Silverstein AM. Local GVH reactions within the anterior chamber of the eve: the formation of corneal endothelial pocks. Invest Ophthalmol Visual Sci 1975: 14: 64(1)-7.

18 Khoudadhoust AA. Silverstein AM. Studies on the nature of privilege enjoved bv corneal allografts. Invest Ophthalmol Visual Sci 1972; 11: 137-48.

19 Lorenzetti DWC. Kaufman HE. Experimental production of graft reactions with suppression by topical steroids. Arch Ophthalmol 1966: 76: 274-81

20) Basu PK. Studies on the mechanism of corneal graft reaction using simplified systems. Proceedings of the 2nd International Corneo-plastic Conference, 1967. Oxford: Pergamon. 1969: $163-72$.

21 Polak FM. Effect of azathioprine (Imuran) on corneal graft reaction. Am J Ophthalmol 1967: 64: 233-41.

22 Polak FM. Inhibition of immune corneal graft rejection hv azathioprine (Imuran). Arch Ophthalmol 1965: 74: 683-9

23 Fleming JC. Reid FR. Wood TO. Prevention of immune graft rejection after corneal transplantation. Am J Ophthalmol 1979: 88: $97-101$.

24 Coster DJ. Shepherd WFI. Chin-Fook T. Rice NSC. Jones BR. Prolonged survival of corneal allografts in rabbits treated with cvclosporin A. Lancet 1979: ii: 688-9.

25 Shepherd WFI. Coster DJ. Chin Fook T. Rice NSC. Jones BR. Effect of cyclosporin-A on the survival of corneal grafts in rabbits. Br J Ophthalmol 1980): 64: 148-53.

26 Editorial. Lancet 1979; ii: 779-80.

27 Markwick JR. Chamber JD. Hobbs JR. Pegrum GD. Timing of cyclosporin-A therapy for abrogation of HVG and GVY responses in rats. Lancet 1979: ii: 10.37 .

28 Silverstein AM. Khoudadhoust AA. Transplantation immunohiology of the cornea. In: Corneal Graft Failure. CIBA Foundation Symposium: Amsterdam: Associated Scientific Publishers. 1973: 105-25. 
29 Jones BR. Present knowledge and problems of corneal graft failure. In: Corneal Graft Failure. CIBA Foundation Symposium. Amsterdam: Associated Scientific Publishers. 1973: 349-54.

30) Stark WJ. Taylor HR. Bias WB. Maumenee AE. Histocompatibility (HLA) antigens and keratoplasty. Am J Ophthalmol 1978; 86: $595-6(1) 4$.

31 Ehlers N. Ahrons S. Corneal transplantation and histocompatibility. Acta Ophthalmol (Kbh) 1971: 49: 513-27.

32 Foster CS. Allansmith MR. Lack of blood group antigen A on human corneal endothelium. Am J Ophthalmol 1979;87: 165-70.

33 Salishury JD, Gebhardt BM. Blood group antigens on human corneal cells demonstrated by immunoperoxidase staining. Am J Ophthalmol 1981; 91: 46-50.

34 Polack FM. Corneal graft rejection: clinico-pathological correlation. In: Corneal Graft Failure. CIBA Foundation Symposium. Amsterdam: Associated Scientific Publishers. 1973: 130.

35 Khoudadhoust AA. Silverstein AM. The survival and rejection of epithelium in experimental corneal transplants. Invest Ophthalmol Visual Sci 1969: 8: 169-79.

36 Hunter PA. Wilhelmus KR. Rice NSC. Jones BR. CvclosporinA applied topically to the recipient eve inhibits corneal graft rejection. Clin Exp Immunol 1981: 45: 173-7.

37 Green CJ. Allison AC. Precious S. Induction of specific tolerance in rabbits by kidnev allografting and short periods of cvclosporinA treatment. Lancet 1979: ii: 123-5.

38 Coster DJ. Factors affecting the outcome of corneal transplantation. Ann R Coll Surg Engl 1981: 63: 91-7. 